УДК 615.32:547.9+543.544

\title{
КОЛИЧЕСТВЕННОЕ ОПРЕДЕЛЕНИЕ АРБУТИНА В ЛИСТЬЯХ ТОЛОКНЯНКИ ОБЫКНОВЕННОЙ
}

\author{
() В.А. Куркин ${ }^{1 *}$, Т.К. Рязанова ${ }^{1}$, И.А. Платонов ${ }^{2}$, Л.В. Павлова ${ }^{2}$ \\ ${ }^{1}$ Самарский государственный медицинский университет, ул. Чапаевская, 89, \\ Самара, 443099 (Россия), e-mail: Kurkinvladimir@yandex.ru \\ ${ }^{2}$ Самарский государственный аэрокосмический университет им. академика \\ С.П. Королева, Московское шоссе, 34, Самара, 443086 (Россия)
}

\begin{abstract}
Разработана методика количественного определения содержания арбутина в листьях толокнянки обыкновенной (Arctostaphylos uva-ursi (L.) Spreng.) методом обращенно-фазовой ВЭЖХ и обоснованы оптимальные условия экстракции арбутина из сырья данного растения (экстрагент - 40\% спирт этиловый, соотношение «сырье : экстрагент»-

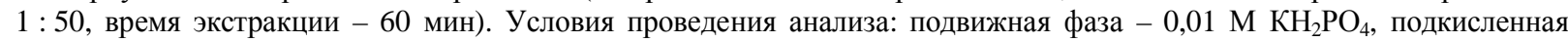
$\mathrm{H}_{3} \mathrm{PO}_{4}$ до $\mathrm{pH} 3,00 \pm 0,01$, и ацетонитрил (9:1); расход подвижной фазы: 0,6 мл/мин; детекция при 280 нм. Определено, что ошибка единичного определения содержания арбутина в листьях толокнянки обыкновенной с доверительной вероятностью 95\% составляет $\pm 3,14 \%$. Содержание арбутина в листьях толокнянки варьирует от $10,85 \pm 0,24 \%$ до $11,16 \pm 0,35 \%$.
\end{abstract}

Ключевые слова: толокнянка обыкновенная, Arctostaphylos uva-ursi (L.) Spreng., арбутин, ВЭЖХ-анализ, спектрофотометрия, йодометрия, стандартизация.

\section{Введение}

В настоящее время актуальным направлением при исследовании лекарственного растительного сырья (ЛРС) является разработка новых подходов к стандартизации, отвечающих современным требованиям к специфичности, воспроизводимости и точности методик анализа, и использование этих подходов при составлении нормативной документации. Одним из основных вопросов, возникающих при разработке методов анализа ЛРС, является обоснование группы биологически активных соединений (БАС), по которой будет осуществляться стандартизация.

Листья толокнянки обыкновенной [Arctostaphylos uva-ursi (L.) Spreng.] издавна используются в традиционной медицине в качестве мочегонного, антимикробного и противовоспалительного средства при различных заболеваниях мочеполового тракта $[1,2]$. Их действие связывают с содержащимися в них простыми фенолами (гидрохинон и его $\beta$-D-глюкопиранозид - арбутин) [1] (рис. 1).

Стандартизацию листьев толокнянки согласно Государственной Фармакопее СССР XI издания осуществляют по содержанию арбутина йодометрическим титрованием [3]. Данная методика предусматривает несколько стадий (осаждение полифенолов, гидролиз арбутина, восстановление хинонов) и достаточно трудоемка, что снижает ее воспроизводимость и увеличивает ошибку метода $[4,5]$.

Куркин Владимир Александрович - заведующий кафедрой фармакогнозии с ботаникой и основами фитотерапии, доктор фармацевтических наук, профессор, тел.: (846)-260-33-59, e-mail: Kurkinvladimir@yandex.ru Рязанова Татьяна Константиновна - аспирант кафедры фармакогнозии с ботаникой и основами фитотерапии, тел.: (846)-260-33-59, e-mail: ryazantatyana@mail.ru Платонов Игорь Артемьевич - заведующий кафедрой химии, доктор технических наук, профессор, тел.: (846)-335-18-06, e-mail: pia@ ssau.ru Павлова Лариса Викторовна - аспирант кафедры химии, тел.: (846)-335-18-06, e-mail: pia@ ssau.ru<smiles>Oc1ccc(O)cc1</smiles>

Гидрохинон

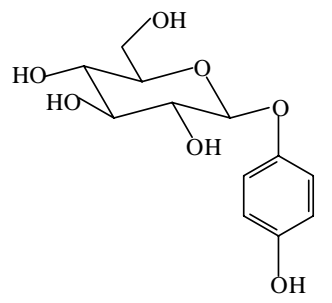

Арбутин

Рис. 1. Простые фенолы листьев толокнянки обыкновенной

\footnotetext{
* Автор, с которым следует вести переписку.
} 
В европейской и американской растительных фармакопеях определение арбутина проводят методом ВЭЖХ $[6,7]$. В европейской фармакопее сырье подвергают двукратной экстракции водой очищенной, в качестве неподвижной фазы используют октадецилсиликагель, элюируют в изократическом режиме, подвижная фаза - смесь воды и метанола (90:10) [6]. В американской растительной фармакопее в качестве неподвижной фазы также используют октадецилсиликагель, предусмотрен градиентный режим элюирования смесями метилового спирта и воды очищенной [7]. Детектируют при длине волны 280 нм. Во всех этих методиках предусмотрено использование метанола, обращение с которым требует выполнения определенных условий.

Для определения арбутина в лекарственном растительном сырье известны также фотоколориметрический, основанный на реакции азосочетания арбутина с азосоединением, и хроматоспектрофотометрический методы $[5,8]$. В связи с этим актуальным является решение проблемы стандартизации листьев толокнянки обыкновенной в плане обоснования методик анализа, показателей качества и нормативной документации на данное сырье.

Цель настоящего исследования - обоснование методики количественного определения арбутина в листьях толокнянки обыкновенной.

\section{Экспериментальная часть}

Объектами исследования являлись листья толокнянки обыкновенной, заготовленные ручным способом в Республике Марий Эл (2013 г.). В исследовании применяли стандартный образец арбутина (производства «Sigma-Aldrich», США), а также рабочий стандартный образец арбутина, полученный с использованием колоночной хроматографии и перекристаллизации.

В исследовании применяли методы тонкослойной хроматографии (ТCX), адсорбционной жидкостной колоночной хроматографии, УФ-спектроскопии и ВЭЖХ. При ТСХ-анализе использовали хроматографические пластины «Сорбфил ПТСХ-АФ-А-УФ». Детекцию проводили путем просмотра хроматограммы при видимом свете и при в УФ-свете при длине волны 254 и 366 нм и после обработки раствором диазобензолсульфокислоты в насыщенном растворе натрия карбоната.

Регистрацию спектров проводили с помощью спектрофотометра «Specord 40» (Analytik Jena) в диапазоне длин волн 190-500 нм. ВЭЖХ-анализ проводили на жидкостном хроматографе Biotronic; хроматографическая колонка Phenomenex Luna C18(2) (250 мм × 4,6 мм, 5 мкм), элюент А - ацетонитрил; элюент В $0,01 \mathrm{M} \mathrm{KH}_{2} \mathrm{PO}_{4}$, подкисленный $\mathrm{H}_{3} \mathrm{PO}_{4}$ до $\mathrm{pH} 3,00 \pm 0,01$, расход подвижной фазы 0,6 мл/мин, объем инжектируемой пробы 20 мкл. Режим элюирования - градиентный, двухступенчатый: элюент А $20 \% 9$ мин; подъем до $40 \%$ за 1 мин, 20 мин - 40\% А. При анализе извлечений после фильтрования через слой алюминия оксида (х.ч., нейтральный II по Брокману) элюировали в изократическом режиме подвижной фазой с содержанием ацетонитрила 10\%. Рабочая длина волны 280 нм была выбрана на основании спектра поглощения рабочего стандартного образца арбутина (рис. 2), выделенного из листьев толокнянки.

На предварительном этапе нами был получен рабочий стандартный образец арбутина. Для этого получали водное извлечение из листьев толокнянки [соотношение сырье : экстрагент $(1: 5)$ ], упаривали до половины объема и фильтровали через слой алюминия оксида на стеклянном фильтре ПОР 160 диаметром 5 см (высота слоя алюминия оксида -5 см). Полученное извлечение обрабатывали трехкратно смесью спирта этилового с хлороформом $1: 1$, упаривали досуха, арбутин в остатке перекристаллизовывали из смеси спирта этилового с хлороформом. Подлинность подтверждали с помощью метода тонкослойной хроматографии с использованием стандартного образца в различных системах растворителей: хлороформ $96 \%$ спирт этиловый (6:4); хлороформ - 96\% этиловый спирт - вода $(26: 16: 3)$ и $н$-бутанол - ледяная уксусная кислота - вода $(4: 1: 2)$. В УФ-спектре арбутина имеются характерные максимумы поглощения при $228 \pm 2$ и $281 \pm 2$ нм (см. рис. 2).

Определение арбутина проводили с использованием фармакопейной методики (йодометрическое титрование), прямой спектрофотометрии после фильтрования через слой алюминия оксида при аналитической длине волны 280 нм и методом ВЭЖХ на обращено-фазовой колонке; подвижная фаза $0,01 \mathrm{M}$ $\mathrm{KH}_{2} \mathrm{PO}_{4}$, подкисленный $\mathrm{H}_{3} \mathrm{PO}_{4}$ до $\mathrm{pH} 3,00 \pm 0,01$, и ацетонитрил $(9: 1)$.

Содержание арбутина в исследуемом образце лекарственного растительного сырья методом йодометрического титрования составило $10,59 \pm 0,70 \%$. Ошибка единичного определения арбутина в листьях толокнянки обыкновенной с доверительной вероятностью 95\% составляет 6,61\%.

Спектрофотометрическое определение проводили при аналитической длине волны 281 нм после фильтрования через слой алюминия оксида с использованием полученного значения удельного показателя поглоще-

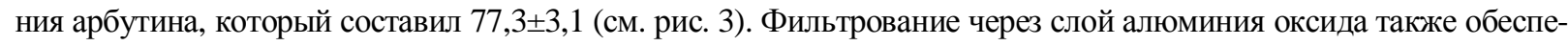


чивает более высокую специфичность метода по отношению к определяемому соединению, однако, на наш взгляд, не исключает вклада в оптическую плотности других веществ, поглощающих при 280 нм.

По результатам спектрофотометрического анализа извлечения из листьев толокнянки, полученного

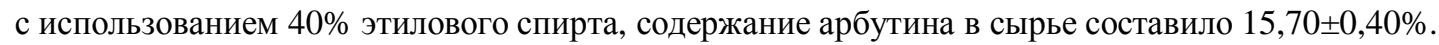

ВЭЖХ-анализ проводили для исходного извлечения (40\% этиловый спирт, соотношение «сырье : экстрагент» - 1:50) с использованием подвижной фазы: $0,01 \mathrm{M} \mathrm{KH}_{2} \mathrm{PO}_{4}$, подкисленный $\mathrm{H}_{3} \mathrm{PO}_{4}$ до $\mathrm{pH}$ $3,00 \pm 0,01$, и ацетонитрил в соотношении $8: 2$ (рис. 4) и для этого же извлечения после фильтрования через слой оксида алюминия - в соотношении $9: 1$ (рис. 5). Количественное определение арбутина проводили по хроматограмме после пропускания через оксид алюминия с использованием подвижной фазы: 0,01 М $\mathrm{KH}_{2} \mathrm{PO}_{4}$, подкисленный $\mathrm{H}_{3} \mathrm{PO}_{4}$ до $\mathrm{pH} 3,00 \pm 0,01$, и ацетонитрил в соотношении $9: 1$ с целью исключения влияния других соединений, а также более четкого отделения анализируемого вещества от сопутствующих соединений (рис. 5). При количественном определении использовали метод абсолютной градуировки, сравнивая площади пиков арбутина в образце и стандарте.

Содержание арбутина в исследуемом образце (экстрагент 40\% этиловый спирт, соотношение «сырье : экстрагент» - 1 : 50), установленное методом ВЭЖХ, составляет 11,16 $\pm 0,35 \%$.

Метрологические характеристики рассматриваемых методик представлены в таблице 1.

Метод ВЭЖХ был выбран нами для разработки методики количественного определения арбутина в листьях толокнянки благодаря своей специфичности, экспрессности, чувствительности.

При разработке методики сравнивались экстракционная способность спиртов различных концентраций, влияние соотношения «сырье : экстрагент» и времени экстрагирования. Определено, что наибольшей экстракционной способностью обладает этиловый спирт 40\%, наибольший выход достигается при соотношении «сырье : экстрагент» - 1 : 50; время экстракции - 60 мин на кипящей водяной бане (табл. 2).

Таким образом, мы предлагаем следующую методику количественного определения арбутина в листьях толокнянки обыкновенной.

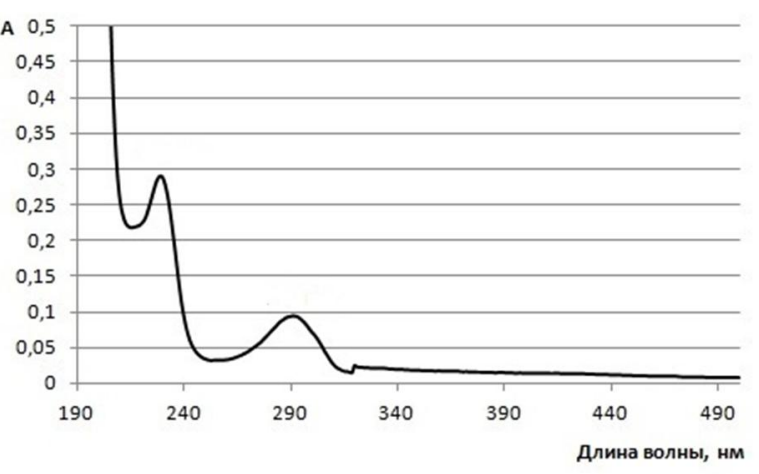

Рис. 2. УФ-спектр рабочего стандартного образца арбутина

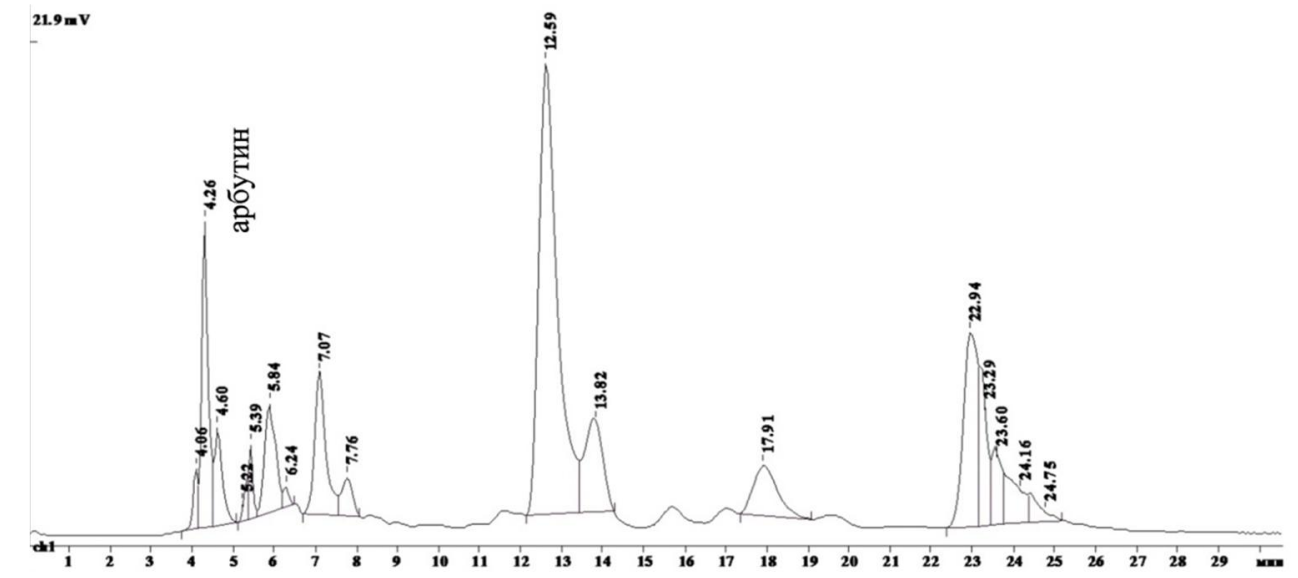

Рис. 4. ВЭЖХ-хроматограмма извлечения на $40 \%$ этиловом спирте из листьев толокнянки обыкновенной

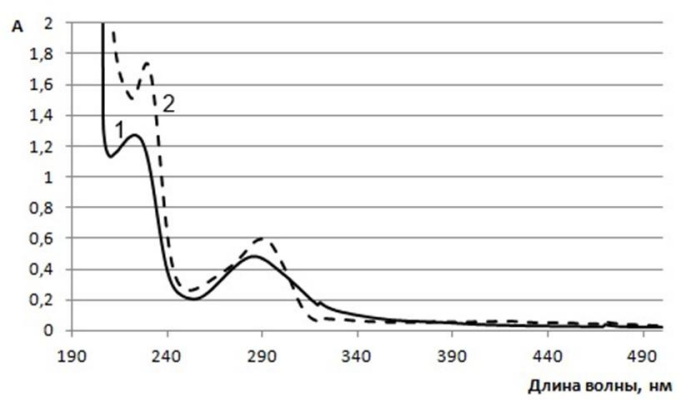

Рис. 3. УФ-спектры исходного извлечения из листьев толокнянки (1) с использованием $40 \%$ спирта этилового и после фильтрования через слой алюминия оксида (2) 


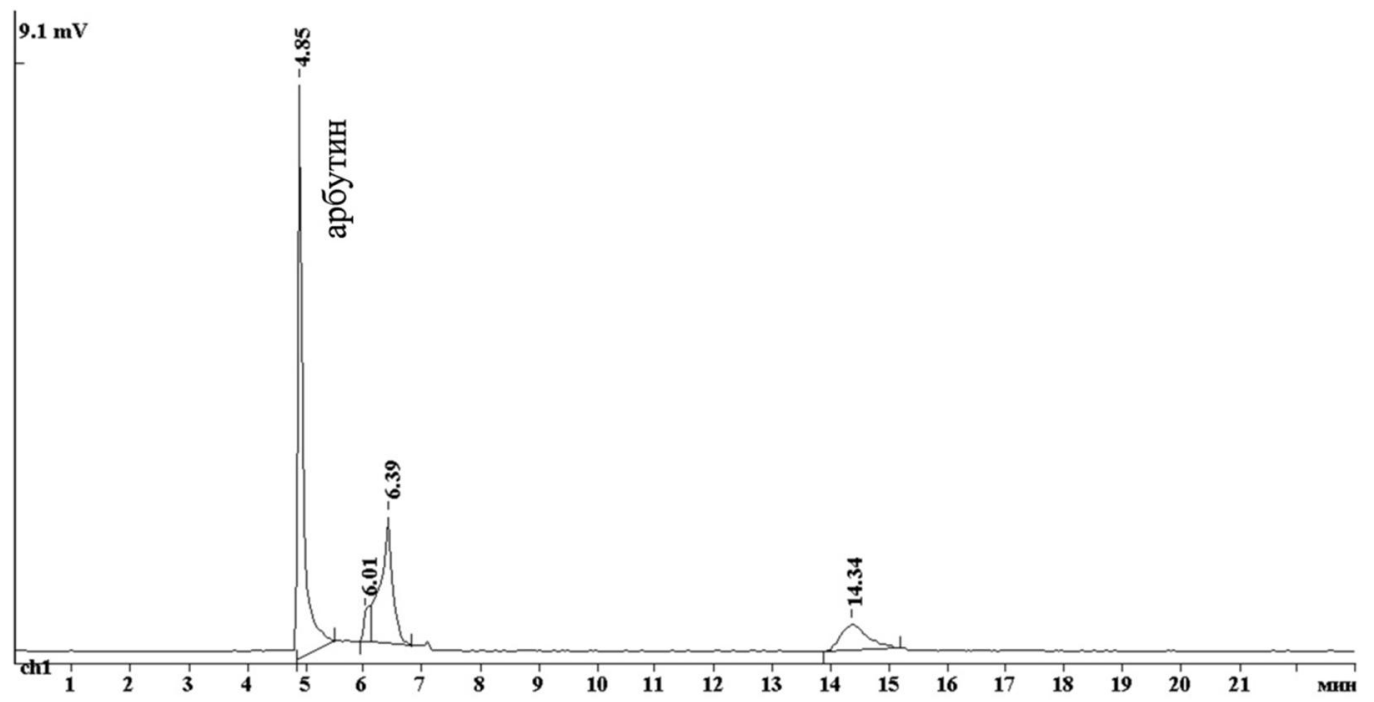

Рис. 5. ВЭЖХ-хроматограмма извлечения на $40 \%$ этиловом спирте из листьев толокнянки обыкновенной после фильтрования через слой алюминия оксида

Таблица 1. Метрологические характеристики методик количественного определения арбутина в листьях толокнянки обыкновенной

\begin{tabular}{l|c|c|c|c|c|c|cc}
\hline \multicolumn{1}{c|}{ Метод } & $f$ & $\bar{X}$ & $S$ & $P, \%$ & $t(P, f)$ & $\Delta X$ & $E, \%$ \\
\hline Йодометрия & 5 & 10,59 & 0,66718 & 95 & 2,57 & 0,70 & 6,61 \\
УФ-спектрометрия & 5 & 15,70 & 0,38124 & 95 & 2,57 & 0,40 & 2,55 \\
ВЭЖХ & 5 & 11,16 & 0,33359 & 95 & 2,57 & 0,35 & 3,14 \\
\hline
\end{tabular}

Таблица 2. Влияние различных факторов на полноту извлечения арбутина из листьев толокнянки обыкновенной

\begin{tabular}{|c|c|c|c|}
\hline Экстрагент & Соотношение сырье :экстрагент & Время экстракции, мин & $\begin{array}{c}\text { Содержание арбутина в пересчете } \\
\text { на абсолютно сухое сырье, \% }\end{array}$ \\
\hline \multicolumn{4}{|c|}{ Влияние экстрагента } \\
\hline $70 \%$ этанол & $1: 50$ & 60 & $9,84 \pm 0,27$ \\
\hline $40 \%$ этанол & $1: 50$ & 60 & $11,16 \pm 0,35$ \\
\hline вода & $1: 50$ & 60 & $10,26 \pm 0,38$ \\
\hline \multicolumn{4}{|c|}{ Влияние времени экстрагирования } \\
\hline $40 \%$ этанол & $1: 50$ & 30 & $9,67 \pm 0,38$ \\
\hline $40 \%$ этанол & $1: 50$ & 60 & $11,16 \pm 0,35$ \\
\hline $40 \%$ этанол & $1: 50$ & 90 & $10,72 \pm 0,34$ \\
\hline \multicolumn{4}{|c|}{ Влияние соотношения сырье : экстрагент } \\
\hline $40 \%$ этанол & $1: 30$ & 60 & $10,72 \pm 0,27$ \\
\hline $40 \%$ этанол & $1: 50$ & 60 & $11,16 \pm 0,35$ \\
\hline 40\% этанол & $1: 100$ & 60 & $10,34 \pm 0,25$ \\
\hline
\end{tabular}

Методика количественного определения арбутина в листьях толокнянки. Около 1 г (точная навеска) сырья, измельченного и просеянного через сито с диаметром отверстий 1 мм, помещают в коническую колбу со шлифом вместимостью 100 мл, добавляют 50 мл 40\% этилового спирта. Колбу закрывают пробкой и взвешивают на тарирных весах с точностью до $\pm 0,01$ г. Колбу присоединяют к обратному холодильнику и нагревают на кипящей водяной бане в течение 60 мин. Затем колбу охлаждают до комнатной температуры в течение 30 мин, закрывают той же пробкой, снова взвешивают и восполняют недостающий экстрагент 40\% этиловым спиртом. Извлечение фильтруют через бумажный фильтр (марки «Красная лента»).

5 мл полученного извлечения наносят на слой оксида алюминия (х.ч., нейтральный II по Брокману) высотой 0,5 см в стеклянном фильтре ПОР 100 диаметром 2 см и промывают 20 мл $40 \%$ этилового спирта в мерную колбу вместимостью 25 мл; затем доводят 40\% этиловым спиртом до метки и перемешивают. Полученный раствор инжектируют в хроматограф с УФ-детектором. Объем вводимой пробы составляет 20 мкл. 
Приготовление рабочего стандартного образияа арбутина: 20,00 мг (точная навеска) стандартного образца арбутина помещают в мерную колбу вместимостью 25 мл, растворяют в 40\% спирте этиловом и доводят растворителем до метки, перемешивают. Инжектируют 20 мкл полученного раствора. Объем вводимой пробы составляет 20 мкл.

Хроматографические условия: колонка: 250 мм × 4,6 мм, с октадецилсиликагелем (С18), 5 мкм; температура колонки: комнатная; подвижная фаза: 0,01 $\mathrm{M} \mathrm{KH}_{2} \mathrm{PO}_{4}$, подкисленный $\mathrm{H}_{3} \mathrm{PO}_{4}$ до $\mathrm{pH} 3,0$, и ацетонитрил (9 : 1); расход подвижной фазы: 0,6 мл/мин; детектор: спектрофотометрический, 280 нм.

Расчет количественного содержания арбутина проводят по формуле

$$
\mathrm{X}=\frac{S * m_{s t} * 0,02 * 25 * 50 * 100 * 100}{S_{S t} * m * 25 * 0,02 * 5 *(100-W)}=\frac{S * m_{s t} * 100000}{S_{S t} * m *(100-W)},
$$

где $\mathrm{S}$ - площадь пика арбутина на хроматограмме испытуемого образца; $\mathrm{S}_{\mathrm{st}}$ - площадь пика арбутина на хроматограмме стандартного образца; $\mathrm{m}$ - навеска сырья, г; $\mathrm{m}_{\mathrm{st}}-$ масса арбутина в растворе стандартного образца, г; W - влажность сырья, \%.

Метрологические характеристики предлагаемого метода представлены в таблице 1.

\section{Bbыводы}

1. Обоснованы оптимальные условия экстракции арбутина из листьев толокнянки: экстрагент - 40\% этиловый спирт; время экстракции - 60 мин на кипящей водяной бане; соотношение «сырье : экстрагент» - $1: 50$.

2. Предложена методика количественного определения арбутина методом обращенно-фазовой

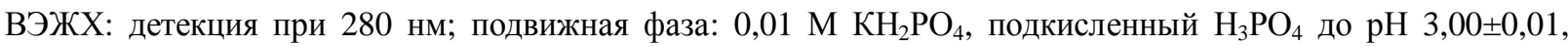
и ацетонитрил (9:1); расход подвижной фазы: 0,6 мл/мин. Содержание арбутина в сырье, установленное

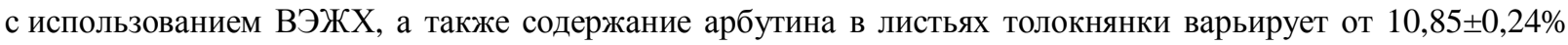
до $11,16 \pm 0,35 \%$.

\section{Список литературы}

1. Куркин В.А. Фармакогнозия : учебник для студентов фармацевтических вузов (факультетов.). 2-е изд., перераб. и доп. Самара, 2007. 1239 с.

2. Куркин В.А. Основы фитотерапии : учебное пособие для студентов фармацевтических вузов. Самара, 2009. 963 c.

3. Государственная фармакопея СССР: Вып. 2. Общие методы анализа. Лекарственное растительное сырье / МЗ СССР. 11-е изд., доп. М., 1990. 400 с.

4. Охрименко Л.П., Калинкина Г.И., Дмитрук С.Е. Сравнительное исследование толокнянки, брусники и близких к ним видов, произрастающих в Республике Саха (Якутия) // Химия растительного сырья. 2005. №1. С. 31-35.

5. Федосеева Л.М. Анализ арбутина подземных и надземных вегетативных органов бадана толстолистного (Bergenia crassifolia (L.) Fitsch.), произрастающего на Алтае // Химия растительного сырья. 2003. №1. С. 73-77.

6. Ph.Eur. 2012: European Pharmacopoeia, $8^{\text {th }}$ edition. Strasbourg (FR): Directorate for the Quality of Medicines and HealthCare of the Council of Europe (EDQM), 2012. Pp. 1162-1163.

7. Uva Ursi Leaf (Arctostaphylos uva-ursi (L.) Spreng). Standards of analysis, quality control, and therapeutic // American Herbal Pharmacopoeia. 2008.

8. Абдуллина С.Г. и др. Фармацевтический анализ / под ред.: Г.К. Будникова, С.Ю. Гармонова. М., 2013. С. 316-319. 
Kurkin V.A. ${ }^{{ }^{*}}$, Ryazanova T.K. ${ }^{I}$, Platonov I.A. ${ }^{2}$, Pavlova L.V. ${ }^{2}$ QUANTITATIVE DETERMINATION OF ARBUTIN IN THE LEAVES OF ARCTOSTAPHYLOS UVA-URSI (L.) SPRENG.

${ }^{I}$ Samara State Medical University, Chapaevskaia st., 89, Samara, 443099 (Russia),e-mail: Kurkinvladimir@yandex.ru

${ }^{2}$ Samara State Aerospace University named Academician S.P. Korolev, Moskovskoe shosse, 34, Samara, 443086 (Russia)

The method of quantitative determination of arbutin in leaves of bearberry (Arctostaphylos uva-ursi (L.) Spreng.) using reverse-phase HPLC and justified optimal conditions of extraction of arbutin from raw materials of plants (extractant - 40\% ethyl alcohol; the extraction time $-60 \mathrm{~min}$ a boiling water bath; the ratio of «raw material : extractant» $-1: 50)$. Conditions of carrying out of the analysis: the mobile phase $0,01 \mathrm{M} \mathrm{KH}_{2} \mathrm{PO}_{4}$ acidified $\mathrm{H}_{3} \mathrm{PO}_{4}$ to $\mathrm{pH} 3,00 \pm$ of 0,01 , and acetonitrile $(9: 1)$; the flow of the mobile phase: $0,6 \mathrm{ml} / \mathrm{min}$; detection at $280 \mathrm{~nm}$. It is determined that the error of a single definition of the contents of arbutin in leaves of bearberry with confidence probability of $95 \%$ is $\pm 3,14 \%$. The content of arbutin in leaves of bearberry varies from $10,85 \pm 0,24 \%$ to $11,16 \pm 0,35 \%$.

Keywords: bearberry, Arctostaphylos uva-ursi (L.) Spreng., leaves, arbutin, HPLC-analysis, spectrophotometry, iodimetry, standardization.

\section{References}

1. Kurkin V.A. Farmakognoziia: Uchebnik dlia studentov farmatsevticheskikh vuzov (fakul'tetov.). [Pharmacognosy: the textbook for students of pharmaceutical universities (faculties)]. 2 ed. Samara, 2007. 1239 p. (in Russ.).

2. Kurkin V.A. Osnovy fitoterapii: Uchebnoe posobie dlia studentov farmatsevticheskikh vuzov. [Basics of phytotherapy: Textbook for students of pharmaceutical universities]. Samara, 2009. 963 p. (in Russ.).

3. Gosudarstvennaia farmakopeia SSSR: Vyp. 2. Obshchie metody analiza. Lekarstvennoe rastitel'noe syr'e. [State Pharmacopoeia of the USSR: Vol. 2. General methods of analysis. Medicinal herbs]. 11 ed. Moscow, 1990, 400 p. (in Russ.).

4. Okhrimenko L.P., Kalinkina G.I., Dmitruk S.E. Khimiia rastitel'nogo syr'ia, 2005, no. 1, pp. 31-35. (in Russ.).

5. Fedoseeva L.M. Khimiia rastitel'nogo syr'ia, 2003, no. 1, pp. 73-77. (in Russ.).

6. Ph.Eur. 2012: European Pharmacopoeia, $8^{\text {th }}$ edition. Strasbourg (FR): Directorate for the Quality of Medicines and HealthCare of the Council of Europe (EDQM), 2012. Pp. 1162-1163.

7. Uva Ursi Leaf (Arctostaphylos uva-ursi (L.) Spreng). Standards of analysis, quality control, and therapeutic // American Herbal Pharmacopoeia. 2008.

8. Abdullina S.G. et all. Farmatsevticheskii analiz. [Pharmaceutical analysis]. Ed. G.K. Budnikov, S.Iu. Garmonov. Moscow, 2013, pp. 316-319. (in Russ.).

Received July 1, 2014

Revised October 11, 2014

\footnotetext{
* Corresponding author.
} 